(ICMEP-9)

\title{
Young's modulus of tungsten at elevated temperatures using synchronous laser shadow vibrometry
}

\author{
H. S. Ayoub ${ }^{1}$, Ashraf F. El-sherif ${ }^{2}$, H. H. Hassan ${ }^{3}$, S. A. Khairy ${ }^{4}$ \\ ${ }_{1,3,4}$ Department of Physics, Faculty of Science, Cairo University, Egypt \\ ${ }^{2}$ Laser Photonics Research Center, Engineering Physics Department, \\ Military Technical College, Cairo, Egypt
}

\begin{abstract}
:
This paper presents the use of an improved laser shadowgraphy method for measuring the dynamic elastic moduli of tungsten, from room temperature to near melting point. The method is based on measuring the frequency of impulse induced longitudinal vibration of a tungsten filament, subject to joule heating. The natural resonance frequency of the filament is obtained by lock-in synchronous photo-detection of the laser generated filament shadowgraph. The correlation between the filament natural frequency and its temperature lead to the calculation of shear modulus at variable temperatures, the tensile and bulk modului of tungsten. The results were compared to those obtained by laser Doppler vibrometry of a tungsten wire induced by pulsed current technique. Our method permitted a wider measuring temperature range and an easier calculation procedure. The used setup was simple, non-destructive, non-contacting and accurate, enabling low cost vibrometry measurements that help in future synthesis and test of new grades of refractory materials, deployed as plasma facing material in the latest fusion reactor or super alloys in critical applications.
\end{abstract}

Keywords:

Tungsten, elasticity moduli, elevated temperatures, shadowgraphy, laser vibrometry, lock-in amplifier, low cost.

\section{Background}

As the demand for tungsten and its alloys in engineering and experimental nuclear physics continue to grow, the need for performing more accurate thermo-mechanical testing also increases [1-10]. The most required metallurgic characteristic in this context is the elevated temperature dynamic elasticity [11-13] that helps in developing advanced metallic grads of refractory materials [14-18]. Many technique were developed to measure the dynamic elastic moduli [19-21] but fewer is suitable for elevated temperatures [22-41]. One of the prominent technique used to measure the dynamic young's modulus of tungsten at high stresses and temperatures, is the laser Doppler vibrometry of a wire sample induced by high current pulses [23]. This technique enable measurements in the range from room temperature to $2650 \square \mathrm{C}$. A second order parametric equation is used for fitting the experimentally obtained Young's modulus data over the mentioned thermal range on the form: 
Military Technical College

Kobry Elkobbah,

Cairo, Egypt

April 3-5,2018

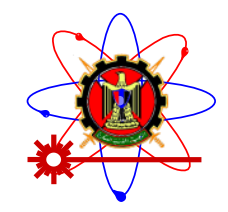

$$
E(T)=a_{0}+a_{1} T+a_{2} T^{2}
$$

$9^{\text {th }}$ International Conference

on Mathematics and

Engineering Physics

(ICMEP-9)

Where $a_{o}, a_{1}$ and $a_{2}$ are the regression constants. This result was achieved using a number of sophisticated equipment ( such as laser Doppler vibrometer, spectrum analyzer, highresolution pyrometer...) and through a complex procedure. This procedure is based on calculating $E$ at a certain temperature $T$ as an equivalent tensile modulus function on the form:

$$
E(T) \equiv F(f(T, n, l), r, \rho(T), v(T), \xi(v))
$$

Where $f$ is radial frequency of the vibrating wire (depends on wire length $l$ and the vibration mode $n), r$ is its radius, $\rho$ is its material density $v$ is the Poisson ratio and $\xi$ is the root of Bessel function. Only two parameters in this method were obtained experimentally, those parameters are $f$ and $T$. the rest are obtained through parameterization of published and reference data, characterizing tungsten. Moreover, $T$ is another implicit function or:

$$
T \equiv F^{*}\left(\varepsilon_{T}(R), I\left(\tau_{e}\right), \omega\right)
$$

Where $F^{*}$ the equivalent temperature function, $\varepsilon_{T}$ is the emissivity of the wire surface at measured temperature (depends on surface roughness $R$ ), the electric current pulse intensity pulse duration $\tau_{e}$ and repetition rate $\omega$.

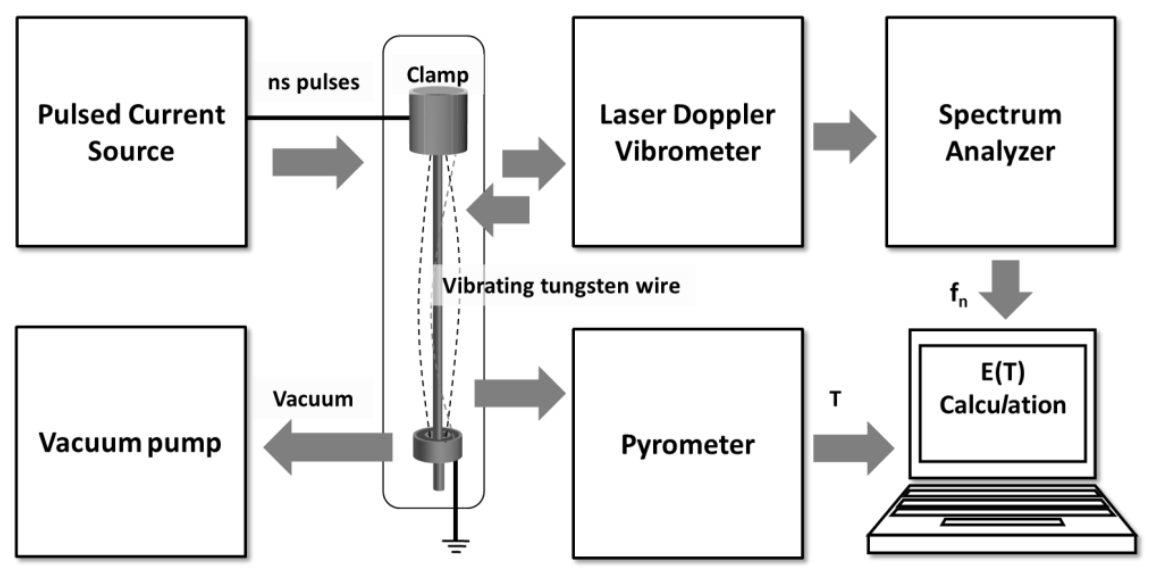

Figure 1. Block diagram representing the measurement of the dynamic Young's modulus of a tungsten wire using laser Doppler vibrometry and pulse current heating technique [23]

So many sources of error are involved in this procedure, where the most important are those based on temperature calibration and non-linear thermal distribution along the wire sample, caused by clamps thermal cooling or "end-loss" [42-47]. Table 1. Shows a summary of the error sources in this procedure

Table 1. Summary of the error sources in LDV-pulse current heating technique 
Military Technical College

Kobry Elkobbah, Cairo, Egypt

April 3-5,2018

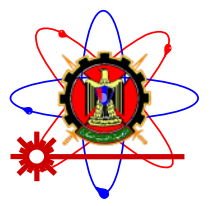

$9^{\text {th }}$ International Conference

on Mathematics and

Engineering Physics

(ICMEP-9)

\begin{tabular}{|c|c|c|}
\hline The error & Origin of the error & $\begin{array}{l}\text { effect on the } \\
\text { measurements }\end{array}$ \\
\hline $\begin{array}{l}\text { Radial velocity and radial } \\
\text { displacement conversion errors. }\end{array}$ & $\begin{array}{l}\text { - } \quad \text { Processing errors. } \\
\text { - Thermal expansion of the wire cross-section. }\end{array}$ & Low \\
\hline $\begin{array}{l}\text { High temperature calibration error in } \\
\text { LDV }\end{array}$ & $\begin{array}{l}\text { - } \quad \text { LDV bad response due to optical saturation at } \\
\text { elevated temperature measurement. } \\
\text { - } \quad \text { Laser speckle noise. }[48,49]\end{array}$ & High \\
\hline $\begin{array}{l}\text { Absolute temperature calibration error } \\
\text { in pyrometer }\end{array}$ & $\begin{array}{l}\text { - } \quad \text { Sample roughness and variable emissivity as a } \\
\text { function of temperature changes. } \\
\text { - } \quad \text { Optical absorption through cavity windows. } \\
\text { - } \quad \text { Slow response of pyro-detector vs. thermal pulses. }\end{array}$ & High \\
\hline End-loss cooling error & $\begin{array}{l}\text { - Thermal distribution gradient due to thermal } \\
\text { cooling of the wire sample through clamps. [43] }\end{array}$ & Very high \\
\hline $\begin{array}{l}\text { Nonlinear vibration modes and } \\
\text { frequency error }\end{array}$ & $\begin{array}{l}\text { - Vibrational multi-degree of freedom due to } \\
\text { nonlinear elasticity distribution along the wire } \\
\text { sample in analogy to the thermal gradient. } \\
\text { - } \text { Friction with the feed through end. }\end{array}$ & Moderate \\
\hline Linear expansion error & - Variation in the wire sample cross-section. & Low \\
\hline $\begin{array}{l}\text { Parametric approximation in } \\
\text { temperature variant inputs (i.e. } \\
\text { emissivity, density and Poisson ratio) }\end{array}$ & - $\quad$ Various data for the same material grade. & Low \\
\hline
\end{tabular}

In this work, we reported a method for measuring the elastic moduli of tungsten at elevated temperatures with good accuracy, excluding the error caused by transient heating and thermal gradient. We propose in this contest to change the shape of the sample from straight wire to coiled filament, to make use of the shading factor discovered by Langmuir at the beginning of the last century [47]. He proved that the thermal gradient of the coiled tungsten wire, is lower than that of the straight wire [42]. We believe that such change should also ease the measurement procedure by decreasing the resonance frequency of the sample and excluding the higher vibration modes.

\section{Theory of the measurement}

The fundamental transverse vibration frequency of a wire string is calculated from the equation

$$
f_{w}=\frac{1}{4 l} \sqrt{\frac{E}{\rho}}
$$

If the same string wire is reformed and coiled to form a fixed-fixed end compression spring (as seen in figure 2) of wire diameter $\mathrm{d}$, coil diameter $\mathrm{D}$, number of turns $\mathrm{N}$ and wire material shear modulus $\mathrm{G}$, then, the frequency of the fundamental longitudinal vibration is given by the equation [50]:

$$
f_{S}=\frac{d}{9 N D^{2}} \sqrt{\frac{G}{\rho}}
$$


Military Technical College

Kobry Elkobbah, Cairo, Egypt

April 3-5,2018

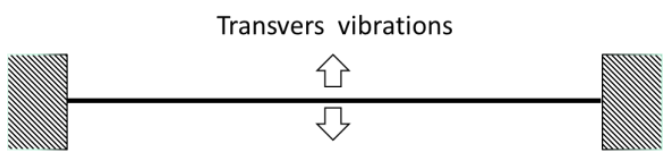

String wire

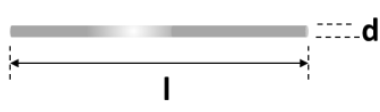

(a)

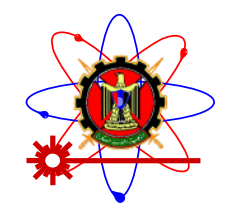

$9^{\text {th }}$ International Conference

on Mathematics and

Engineering Physics

(ICMEP-9)
Longitudinal vibrations

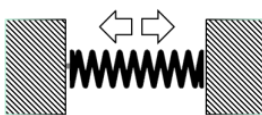

Helical coil

MUWWI:

d

(b)

Figure 2. Changing the symmetry of the sample from (a) String wire with transvers vibration, to (b) Helical coil with longitudinal vibration.

Dividing equation 5 by equation 4 to obtain the frequency ratio for both string and coil symmetry,

$$
\frac{f_{S}}{f_{w}}=\frac{4 d l}{9 N D^{2}} \sqrt{\frac{G}{E}}
$$

But $\mathrm{E}$ and $\mathrm{G}$ are both related by the Poisson ratio equation given by [51];

$$
v=\left(\frac{E}{2 G}\right)-1
$$

Replacing $\mathrm{E}$ and $\mathrm{G}$ in equation 6 by their value in equation 7 we obtain:

$$
\frac{f_{s}}{f_{w}}=\frac{4 d l}{9 N D^{2}} \frac{1}{\sqrt{2(v+1)}}
$$

However, the length of the coil wire can be approximated as a sum of the perimeters of $\mathrm{N}$ circular turns to obtain:

$$
l \approx N \pi D
$$

Replacing equation 9 in equation 8 to obtain:

$$
\frac{f_{s}}{f_{w}}=\frac{4 \pi d}{9 D} \frac{1}{\sqrt{2(v+1)}}
$$

Let $\mu$ representing the spring index of the helical spring like sample

$$
\mu=\frac{D}{d}
$$

By replacing equation 11 in equation 10 and assuming $v=0.28$ to obtain 
Military Technical College

Kobry Elkobbah,

Cairo, Egypt

April 3-5,2018

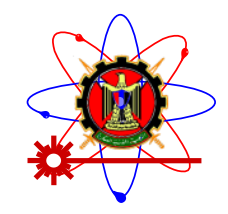

$\frac{f_{s}}{f_{w}}=\frac{5}{18} \mu^{-1}$ $9^{\text {th }}$ International Conference

on Mathematics and

Engineering Physics

(ICMEP-9)

choose $\mu=4$, we conclude that $f_{s}=0.087 f_{w}$ and the resonance frequency of the spring is at least one order of magnitude lower than the frequency of the equivalent string. This result will ease the measurement as well as it will exclude all sophisticated instruments from the test that will directly yields the shear modulus of the sample as given by the following equation obtained from equation 5:

$$
G(T)=\rho(T)\left(\frac{9 l D}{\pi d}\right)^{2} f_{s}^{2}
$$

The density of the sample as a function of temperature is given by the parametric equation [23]:

$$
\rho(T)=19302.9+2.3786 \times 10^{-1} T-2.244 \times 10^{-5} T^{2} \quad \mathrm{~kg} .{ }^{o} \mathrm{C} . \mathrm{m}^{-3}
$$

Once $G(T)$ is obtained, $E(T)$ and $K(T)$ representing the bulk modulus can be easily calculated from the Poisson ratio relations as follows:

$$
E(T)=2 G(T)[v(T)+1]
$$

and

$$
K(T)=2 G(T) \frac{[v(T)+1]}{3[1-2 v(T)]}
$$

Also, the Poisson ratio of tungsten is obtained from the parametric equation [23]:

$$
v(T)=0.279+1.0895 \times 10^{-5} T
$$

Using the formalism of exponents [52], the temperature $T$ of incandescent tungsten coil as a function of it electric resistance $\mathrm{R}$ is calculated from the equation:

$$
\frac{T+273}{T_{o}+273}=\left(\frac{R}{R_{o}}\right)^{0.83}
$$

Where $T_{o}$ and $R_{o}$ represent the room temperature and room temperature resistance of the sample. If we replace $\mathrm{T}_{\mathrm{o}}$ by $27 \square \mathrm{C}$ and $\mathrm{R}$ by the voltage difference applied on the sample $\mathrm{V}$ divided the current passing through its terminals I we obtain:

$$
T=\left[300 \times\left(\frac{V}{I R_{o}}\right)^{0.83}\right]-273
$$

Now we are ready to measure the elastic moduli of tungsten as a function of temperature using only current, voltage and frequency readings, under the effect of mechanical impulse excitation. To retrieve natural vibration frequency data for the incandescent coil, we replaced 
Military Technical College

Kobry Elkobbah,

Cairo, Egypt

April 3-5,2018

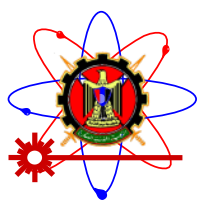

$9^{\text {th }}$ International Conference

on Mathematics and

Engineering Physics

(ICMEP-9)

Doppler vibrometry by laser shadowgraphy, where vibrometry is applied on sample's shadow using a simple optical setup. (Figure 3 shows the block diagram of our proposed method)

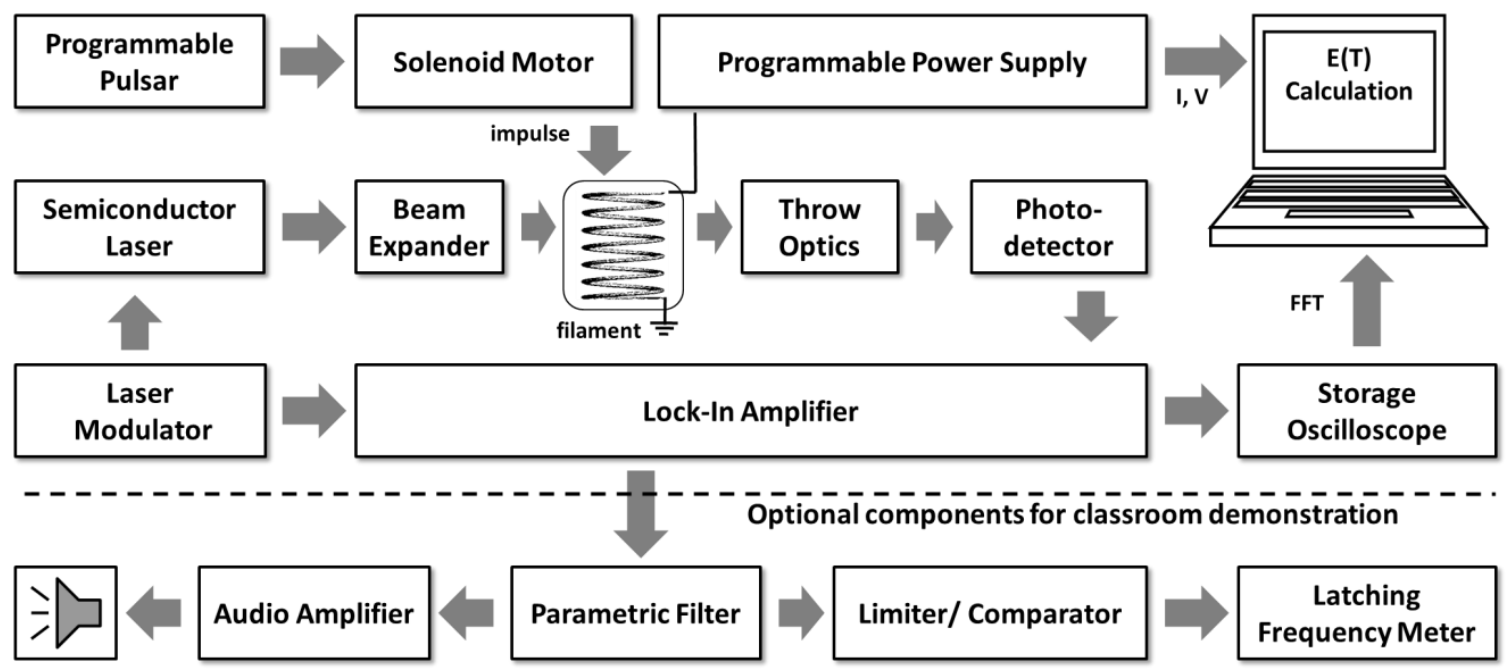

Figure 3. block diagram representing the measurement of the dynamic Young's modulus of a tungsten filament using laser shadow-vibrometry and DC current heating technique.

As mentioned before, we introduced an new idea in shadowgraphy, by using synchronous optical detection under lock-in condition. This improvement enable to exclude laser speckles changes in the shadowgraph background from being detected as popcorn noise. the setup is then able to detect very small shifts in dark shadows positions even in the presence of noisy optical background such as artificial lighting and self-incandescence of the sample, with detection sensitivity approaching 60dB. If the filament is placed in the focal plane of the throw lens of focal length $D_{f}$, then, the shadowgraph of the filament is projected on the photo-detector at throw distance $D_{T}$ With magnification factor $X$ given by the equation:

$$
X=\frac{D_{T}-D_{f}}{D_{f}}
$$

If the filament undergoes a small in-plane position shift due to vibration, then this shift will be magnified at the shadowgraph plan by a factor of $X$. This method can detect small shifts as $1 \times 10^{-7} \mathrm{~m}$ assuming that $X \leq 2000 \times$ and knowing that the theoretical limit is in order of $1 \times 10^{-8} \mathrm{~m}$ [53]. The amplitude of the lock-in output signal is proportional to the magnitude of laser intensity changes at the object's shadow bright/dark boundaries. In order to maximize the output signal, the laser source intensity should be adjusted to bring the photo-detector below saturation. In addition, it is important to place the detector window center at the boundary between the object's shadow and the background laser illumination at the shadowgraph plane. The resulting vibration pattern after one mechanical pulse that is required to excite the free natural resonance of the filament sample may be illustrated by a damping oscillation pattern as shown in figure 4. 
Military Technical College

Kobry Elkobbah,

Cairo, Egypt

April 3-5,2018

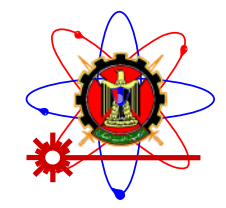

$9^{\text {th }}$ International Conference

on Mathematics and

Engineering Physics

(ICMEP-9)

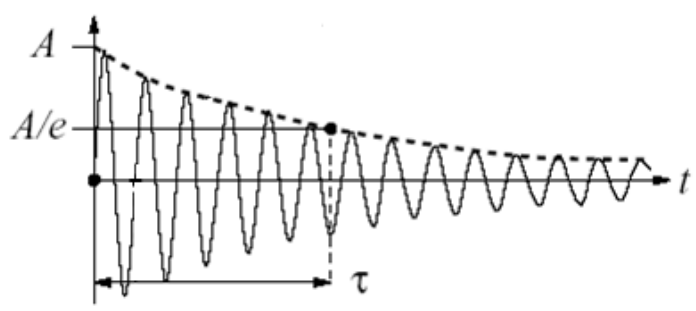

Figure 4 . Free vibration pattern of elastic solids by pulse excitation technique

where the amplitude $\mathrm{A}$ of the oscillation at any time $\mathrm{t}$ after excitation, is given by the equation:

$$
A(t)=A e^{-t / \tau}
$$

$\tau$ is the time interval between $\mathrm{A}$ and $\mathrm{A} / \mathrm{e}$. This time interval depends on the internal friction of the sample that may represented by the inverse of the oscillation quality factor given by the expression [13];

$$
\begin{gathered}
Q^{-1}=\frac{\text { energy dissipated as heat per unit volume over one cyle }}{\text { energy stored per unit volume }} \\
Q^{-1}=\ln \frac{A(T)}{A(\tau)}=T / \pi \tau=1 / \pi \tau f_{0}
\end{gathered}
$$

Where. $T$ is the period of one oscillation of frequency $f$. Hence, we can obtained $Q^{-1}$ graphically from the impulse excitation pattern of the helical filament sample, the relation between the temperature and the internal friction of tungsten shall be revealed. The frequency spectrum of the resonance pattern may be obtained by fast Fourier transforms (FFT). Finally, our method has several major advantages over the pulsed current method. Table 2. summarizes the major parametric differences between laser Doppler vibrometry method and our laser shadow-vibrometry method for measuring the dynamic Young's modulus of tungsten at elevated temperatures.

Table 2. Parametric comparison between laser Doppler vibrometry and laser shadow-vibrometry method

\begin{tabular}{|l|c|c|}
\hline \multicolumn{1}{|c|}{ Parameter } & Doppler vibrometry method & $\begin{array}{c}\text { laser shadowgraphy based- } \\
\text { vibrometry method }\end{array}$ \\
\hline Tungsten sample form & Wire sample & Coiled sample \\
\hline Sample mass & $10^{-3}-10^{-2} \mathrm{~kg}$ & $10^{-4} \mathrm{~kg}$ \\
\hline Sample preparation & Intensive & Dxtensive \\
\hline Heating current type & Pulsed current & few Amperes \\
\hline Current intensity & $10^{3}$ Amperes & Absolute calibration \\
\hline Temperature measurement & Pyrometer & Gaussian \\
\hline Mechanical excitation method & Electric pulse & Laser shadow- vibrometry \\
\hline Pulse shape & Non- Gaussian & Laser intensity variations \\
\hline Frequency detection & Laser Doppler vibrometry & Coil shadow position changes \\
\hline Detected phenomena & Laser frequency changes & Simple \\
\hline Phenomena causality & wire radial velocity changes & Simple \\
\hline FFT signal analysis & Complex & Low \\
\hline Harmonic autocorrelation test & complex & High \\
\hline Temperature gradient & &
\end{tabular}


Military Technical College

Kobry Elkobbah, Cairo, Egypt

April 3-5,2018

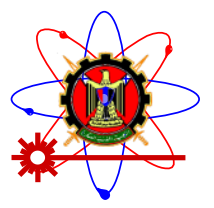

$9^{\text {th }}$ International Conference

on Mathematics and

Engineering Physics

(ICMEP-9)

\begin{tabular}{|l|c|c|}
\hline Frequency range & Ultrasound & Audio \\
\hline Setup cost & High & Low \\
\hline Optical noise rejection & Low & Very high \\
\hline Detector saturation & Very high & Measurable \\
\hline Room temperature elasticity & Only possible & Shear modulus \\
\hline Measured parameter & Young's modulus & Up to 3400 $\square$ c \\
\hline Measurements range & Up to 2650 $\square$ c & Low \\
\hline Cooling & Yes & Not Essential \\
\hline Power Consumed & High & Possible \\
\hline Sample surface roughness & Essential & Controllable \\
\hline Internal friction measurements & Not possible & Selectable \\
\hline Magnitude of Impulse force & Not controllable & Pure mechanical shock \\
\hline Direction of impulse force & Not selectable & Possible \\
\hline Type of the impulse force & Thermal gradient elastic reaction & Not possible \\
\hline Vibration mode control & & \\
\hline
\end{tabular}

\section{Experimental work}

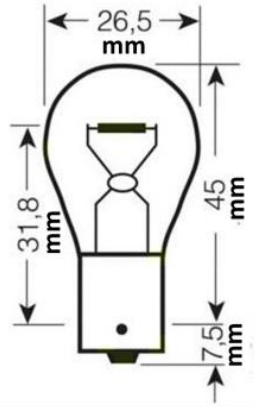

(a)

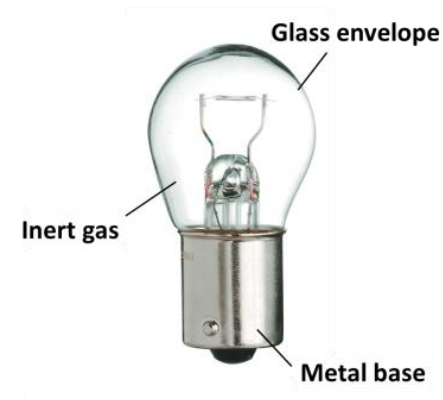

(b)

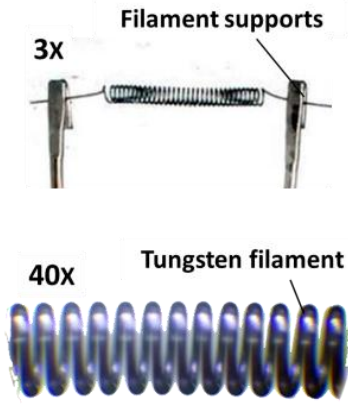

(c)

Figure 5. Experimental tungsten filament of 12 volt lamp (a) BA15 standard stop \& flasher lamp blueprint (b) The basic lamp parts (c) Magnified view of the internal helical filament and its supports.

We designed a simple setup to prove the concept of measurement and to test its accuracy, so we decided to use commercial grade non-sag tungsten (99\% purity) as test material basically used in incandescent lamps. We searched then for the best lamp with nearly ideal geometry and power that met our requirements. We selected a cheap P21W12V automotive incandescent lamp previously studied in many works before [54-60]. This lamp still in production and still sold in worldwide market. As shown in Figure 5.a, the selected lamp is compact, lightweight and has a nearly-spherical transparent glass envelope that permits laser shadowgraphy without distortion. It encloses a horizontal single coiled linear helical filament produced by powder metallurgy (Figure 5.b). This filament is clamped to a very thick refractory clamping supports relative to filament wire diameter which insure that their resonance frequency is so much higher than the frequency of the filament by an order of at least two decades. The contact surface area between the tungsten wire and the clamp is very small leading to a high thermal resistance that keeps the support relatively cold with comparison to the incandescent filament (Figure 5.c). The normal operating temperature of the filament is about $2400^{\circ} \mathrm{C}$, hence we shall overdrive the lamp and exceeding the operating 
Military Technical College

Kobry Elkobbah,

Cairo, Egypt

April 3-5,2018

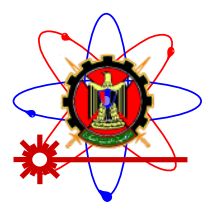

$9^{\text {th }}$ International Conference

on Mathematics and

Engineering Physics

(ICMEP-9)

voltage to increase the heating current till reaching the near melting temperature of tungsten.

Table 3 summarized the basic physical parameters of lamp.

Table 2. Physical characteristics of the P $21 \mathrm{~W} 12 \mathrm{~V}$ automotive tungsten lamp

\begin{tabular}{|l|c|c|l|}
\hline \multicolumn{1}{|c|}{ Room temperature parameter } & Symbol & Value & \multicolumn{1}{c|}{ Unit } \\
\hline Electric resistance & $R$ & 0.5 & $\Omega$ \\
\hline Wire material resistivity & $\rho_{e}$ & $5.65 \times 10^{-8}$ & $\Omega \mathrm{m}^{-1}$ \\
\hline Wire length & $l$ & $6 \times 10^{-2}$ & $\mathrm{~m}$ \\
\hline Wire diameter & $d$ & $9 \times 10^{-5}$ & $\mathrm{~m}$ \\
\hline Coil diameter & $D$ & $5 \times 10^{-4}$ & $\mathrm{~m}$ \\
\hline Spring index & $\mu$ & 0.1 & - \\
\hline Coil length & $L$ & $6 \times 10^{-6}$ & $\mathrm{~m}$ \\
\hline Wire mass & $m$ & $1.1 \times 10^{-5}$ & $\mathrm{~kg}$ \\
\hline Wire material density & $\rho$ & 19300 & $\mathrm{~kg} / \mathrm{m}^{-3}$ \\
\hline Wire shear modulus & $G$ & $1.6 \times 10^{11}$ & $\mathrm{~m}^{-1}$ \\
\hline Filament natural frequency (longitudinal) & $f$ & $<1 \times 10^{3}$ & $\mathrm{~Hz}$ \\
\hline Filament tungsten purity & $\mathrm{W}$ & 99.0 & $\%$ \\
\hline Tungsten filament potassium impurities content & $\mathrm{K}$ & 6 & $\mathrm{ppm}$ \\
\hline Lamp mass & $M$ & 0.015 & $\mathrm{~kg}$ \\
\hline Lamp nominal operating voltage & $V$ & 12 & $\mathrm{~V}$ \\
\hline Lamp nominal operating current & $I$ & 1.45 & $\mathrm{~A}$ \\
\hline Lamp pressure & $P$ & $\leq 1$ & $\mathrm{bar}$ \\
\hline Inert gas type & $A r$ & - & - \\
\hline
\end{tabular}

The lamp sample is placed in a special mounting stage that permitted to a miniature 5volts solenoid motor plunger (type SF11015) to stroke its glass envelope. Each stroke is a 5ms Gaussian shape mechanical pulse along the filament axe that excite flexure vibration. The base of the lamp is fixed to the body of the stage by hard thermal silicon rubber that isolates the vibration of the lamp from the surroundings. The mounting stage enable precise position adjustment of the sample as well as the solenoid to insure best axial alignment. All mounting components are rigid enough to exclude their ultrasonic flexure resonance frequency from being interfered with that of the filament during measurements. 
Military Technical College

Kobry Elkobbah, Cairo, Egypt

April 3-5,2018

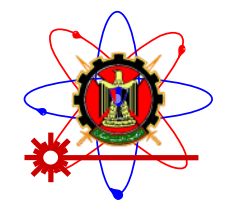

$9^{\text {th }}$ International Conference

on Mathematics and

Engineering Physics

(ICMEP-9)

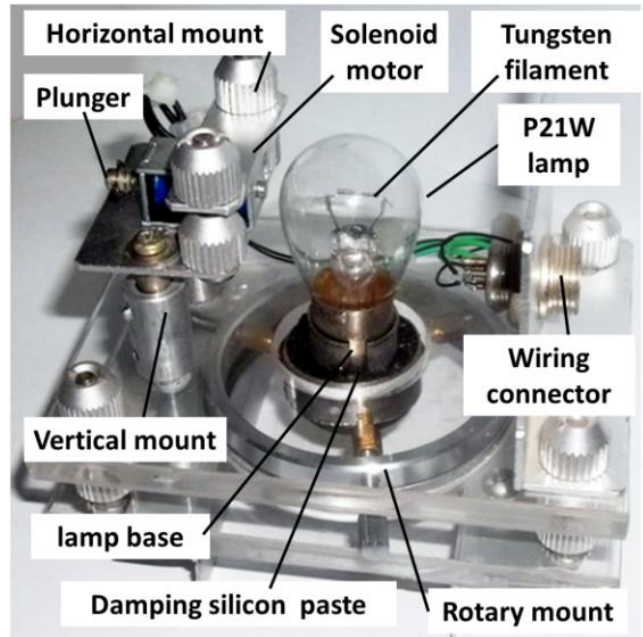

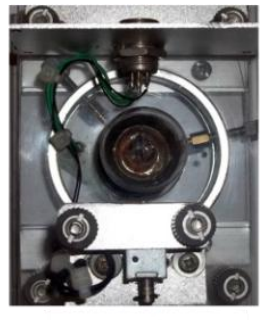

Top view

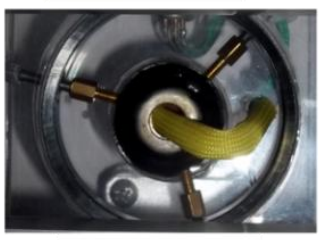

Bottom view

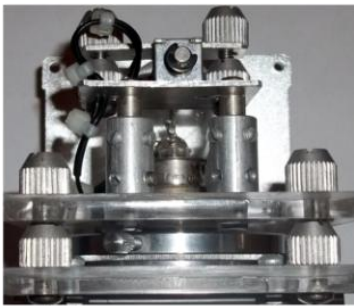

Side view

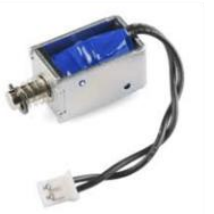

Solenoid motor

Figure 6. The sample mounting stage and its components.

If the solenoid plunger axe is perfectly aligned to the filament axe, the filament is forced to oscillate at the desired longitudinal modes only as shown in figure 7 . The gap between the plunger and the filament must be adjusted also to yield best results. Later we discovered that the gap width can be reduced till vanishing and the filament still excited by the minimum solenoid plunger displacement. If the axis are misaligned then the filament shows undesired complex modes of vibration that is eventually a mix of both transversal and longitudinal modes.
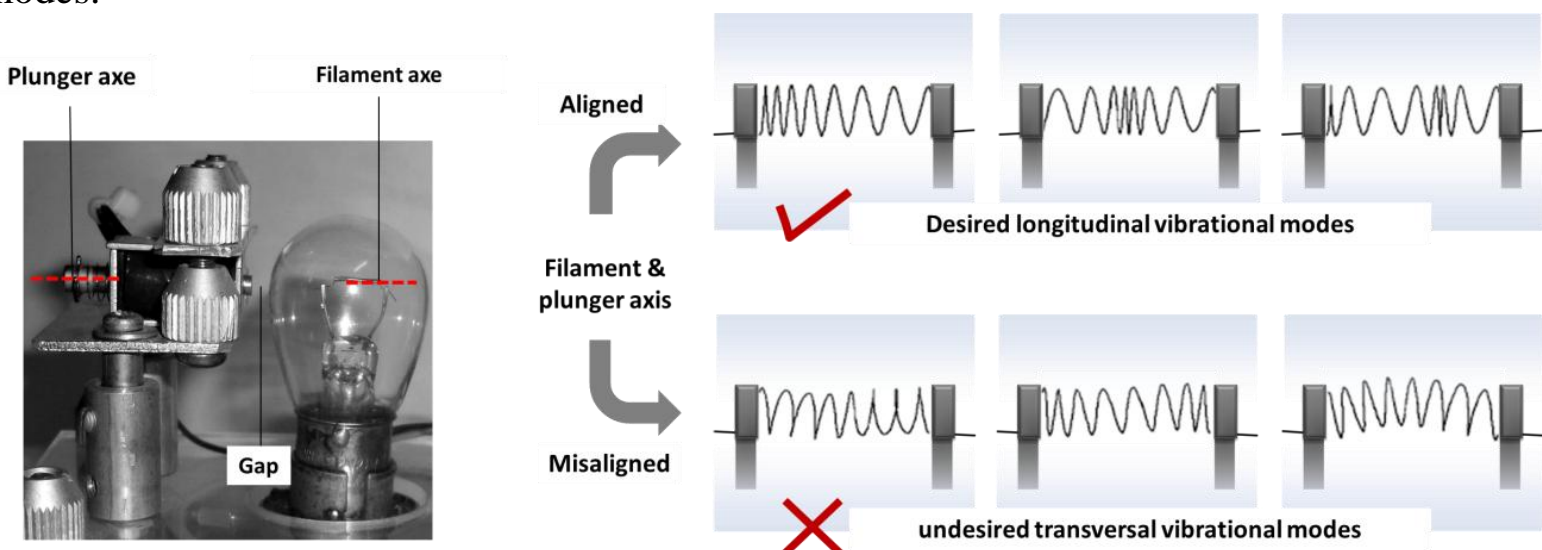

\section{Filament \&} plunger axis

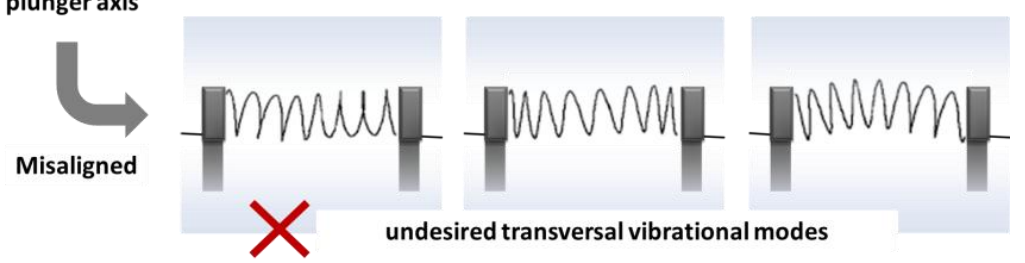

Figure 7. Generation of filament undesired out-of-plan vibrations caused by the misalignment of the solenoid plunger axe to the filament axe

The sample mounting stage is then placed in a laser shadowgraphy-based vibrometer setup that we built as shown in the illustration of figure 8. This setup included a focusable $100 \mathrm{mw}$ semiconductor laser (wavelength $=536 \mathrm{~nm}$ ), electrically modulated with $33 \mathrm{kHz}$ square wave carrier frequency at $90 \%$ modulation depth. The laser beam is expanded into linear beam shape by a rod lens (diameter $=5 \mathrm{~mm}$ ). The expanded beam is backlighting a horizontally the tungsten filament sample. The sample receives a mechanical excitation pulses from a from 
Military Technical College

Kobry Elkobbah, Cairo, Egypt

April 3-5,2018

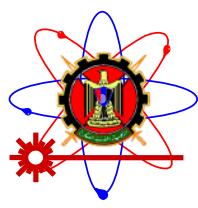

$9^{\text {th }}$ International Conference

on Mathematics and

Engineering Physics

(ICMEP-9)

solenoid motor plunger (stroke time $=5 \mathrm{~ms}$ ). A small focal length convex throw lens (focal length $=20 \mathrm{~mm}$ ) and a pinhole filter (hole diameter $=1 \mathrm{~mm}$ ) are used to generate a shadowgraph for vibrating filament. This shadowgraph is projected $60 \mathrm{~cm}$ away on a ground glass screen in which a photo-detector window (Photodiode type BPW21) is piercing the screen surface. The photo-detection of the filament shadow vibrations is synchronized with the laser modulation to detect the sample resonance signal to be recorded by digital storage oscilloscope.

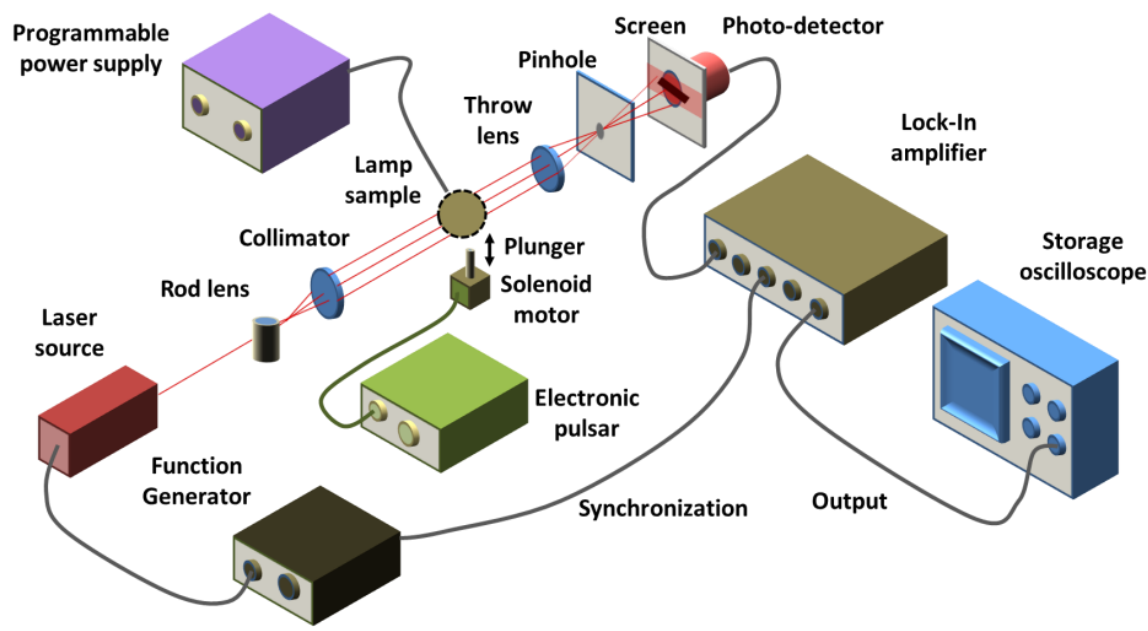

Figure 8. Illustration of the setup basic optical components and instrumentation.

The setup was realized in a lightweight, compact, fast to install and easy to operate layout (figure 9). Most instrumentation were designed and manufactured in the laboratories of the Faculty of Science at Cairo University. The setup was also equipped by a parametric equalizer and an audio amplifier for demonstration of audible filament resonance at different temperatures.
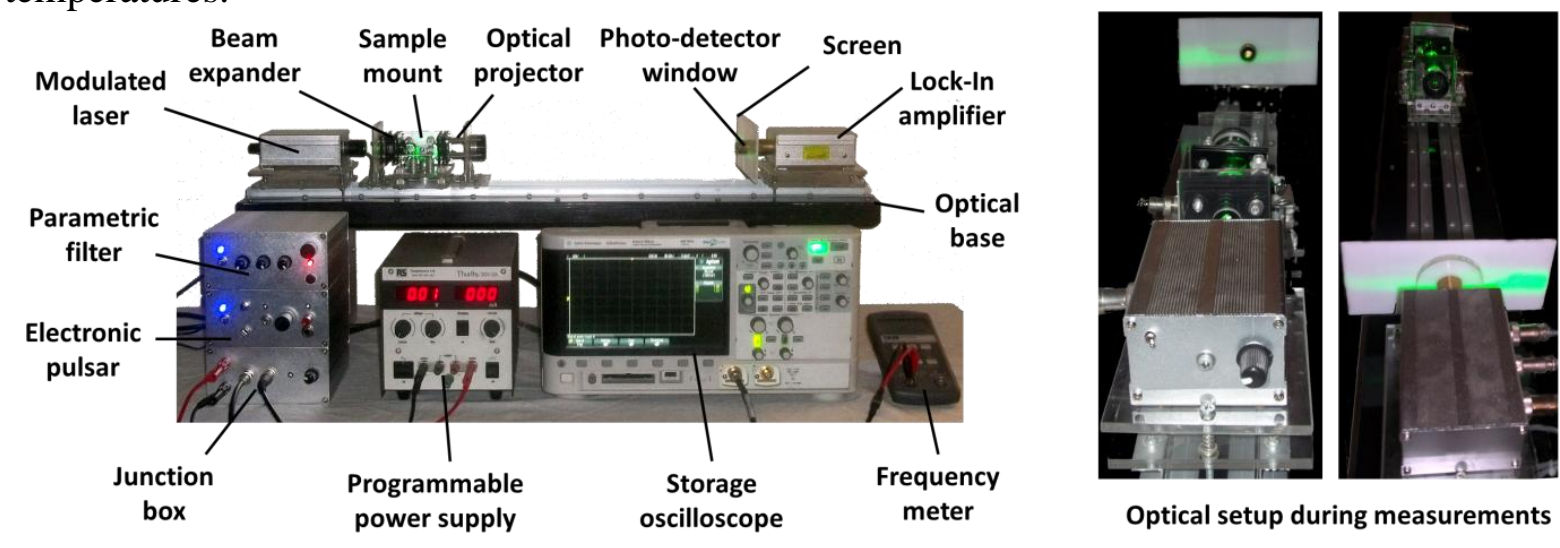

Figure 9. The experimental setup and instrumentation used in this work 
Military Technical College

Kobry Elkobbah,

Cairo, Egypt

April 3-5,2018

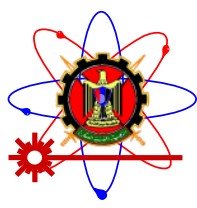

$9^{\text {th }}$ International Conference

on Mathematics and

Engineering Physics

(ICMEP-9)

It is important to mention that the key of success in our measurement is the good optical alignment so that, the filament must completely illuminated by the laser beam (figure 10a) and the center of resulting shadowgram should be projected appropriately on the detector window (figure 10b).

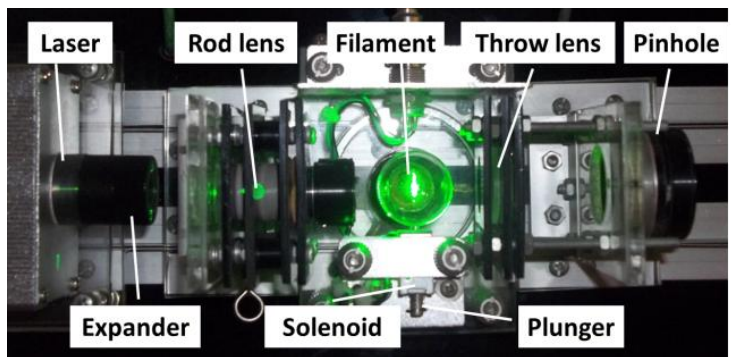

(a)

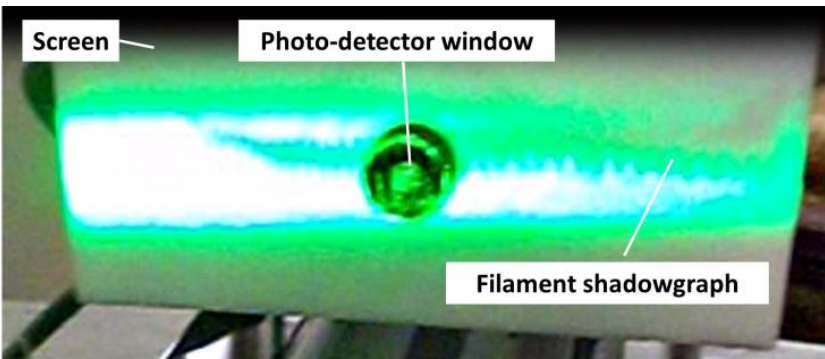

(b)

Figure 10. Close-up showing (a) The optical setup during laser exposure (b) The filament shadowgraph projected on the aiming screen on the photo-detector window.

We started the measurements by heating the filament for at least one hour at temperature of $2400^{\circ} \mathrm{c}$ to sinter the non-sag filament and to allow minimum dislocation defects. At the moment of sudden heating we will notice a minor change in the filament pitch and axial position on the screen due to thermal expansion as we verified in another work [56]. If the alignment process concur some complications then it is recommended to exclude the pinhole filter for a while till finishing all necessary adjustments. Figure 11 show the importance of pinhole filter to screen the luminosity of the filament at incandescence.

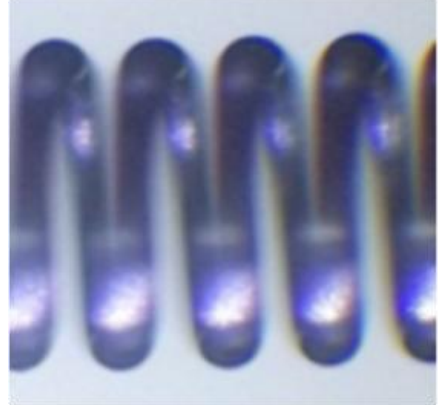

(b)

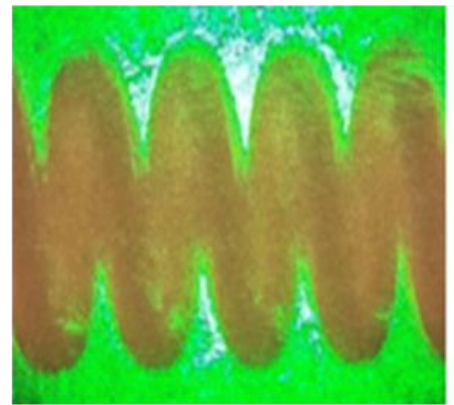

(b)

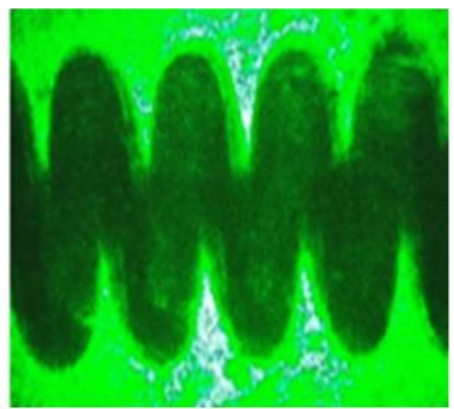

(c)

Figure 11. (a) Magnified traveling microscope image of the tungsten filament part subjected to laser shadowgraphy. (b) The screen projected image of the filament part at incandescence without pinhole filter. (c)

The shadowgraph of the same part of the filament at incandescence after adding the pinhole filter.

We restarted heating the filament slowly and gradually on a 50 or $100 \mathrm{~mA}$ increment. Each time we activated the solenoid and recorded the yielded impulse pattern by the storage oscilloscope till reaching the melting point and the lamp burned-out then. If the burnout profile [61] didn't include filament breakdown and showed only support melting as shown in figure 12 , then the measurement must be repeated with another lamp brand with thicker support stems to ensure attaining the tungsten melting temperature. 
Military Technical College

Kobry Elkobbah,

Cairo, Egypt

April 3-5,2018

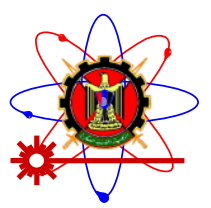

$9^{\text {th }}$ International Conference

on Mathematics and

Engineering Physics

(ICMEP-9)

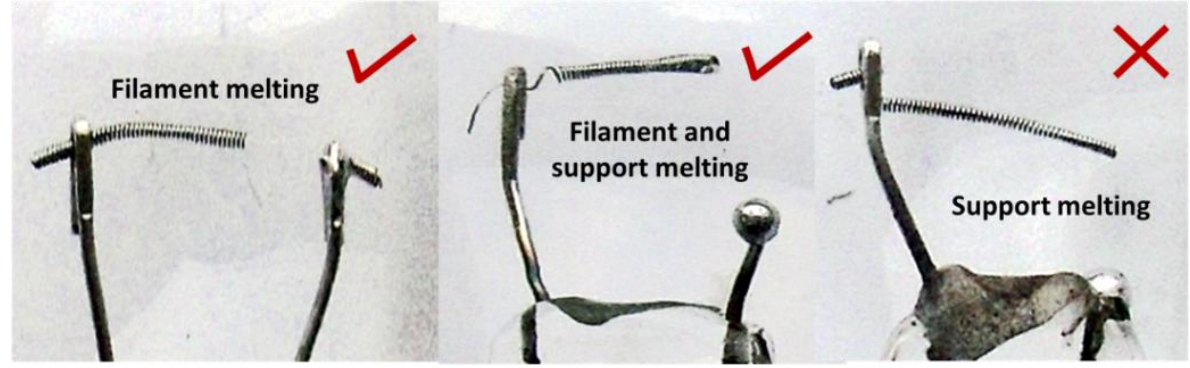

Figure 12. Close-up showing different type of filament lamp samples burnout near melting temperature of tungsten.

All vibration patterns were analyzed by standard Microsoft Office Excel 2010 FFT analysis tool with resolution of 1024 channels to obtain the frequency spectrum of the filament at each temperature.

\section{Results and Discussion}

As seen in figure 13a, the vibration pattern of the tungsten filament at room temperature shows a very long damping time that lasts for several seconds. The time constant is $1.25 \mathrm{~s}$, the quality factor of the oscillation is 3333 and hence, the internal friction is approximately 0.0003 . The dominant oscillation wave form as seen in figure $13 \mathrm{~b}$, is sinusoidal which means that the oscillation mode is purely simple longitudinal.

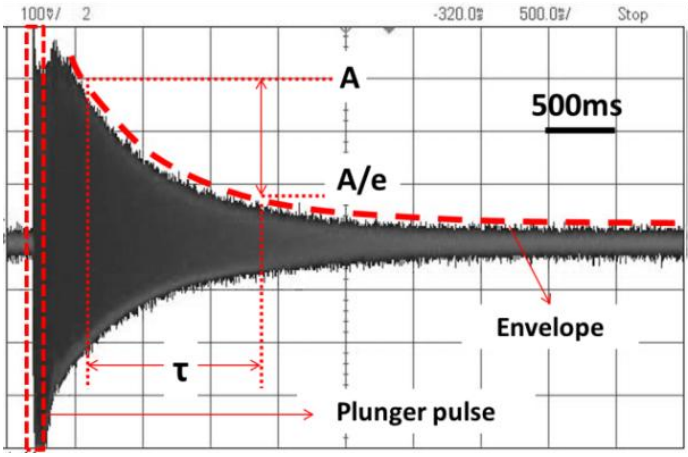

(a)

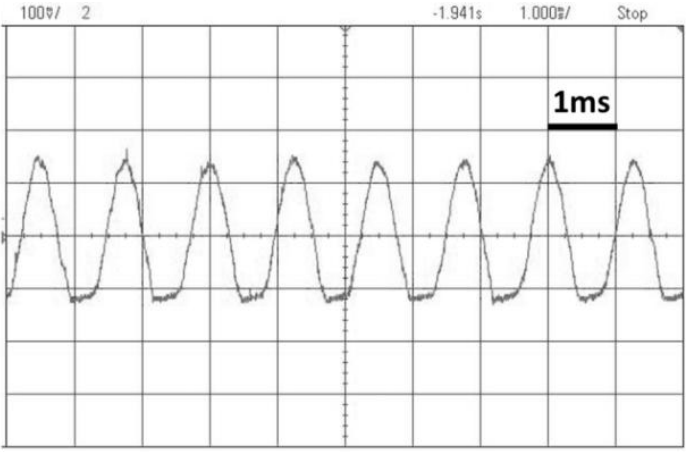

(b)

Figure 13. Oscilloscope picture for the filament impulse vibration pattern at room temperature after a $5 \mathrm{~ms}$ solenoid plunger pulse at different time scales (a) the damping pattern at 500ms /division. (b) The oscillation waveform at center amplitude at $1 \mathrm{~ms} /$ division.

the vibration pattern of the tungsten filament near melting temperature shows a very short damping time that lasts for a fraction of second as seen in figure 14. The time constant is $0.1 \mathrm{~s}$, the quality factor of the oscillation dropped to 129.8 and hence, the internal friction increased to 0.0077 which is 25 times greater than that of room temperature The dominant oscillation wave form as seen in figure 14b, isn't any more sinusoidal which means that the oscillation mode my contain higher harmonics or different modes. 
Military Technical College

Kobry Elkobbah, Cairo, Egypt

April 3-5,2018

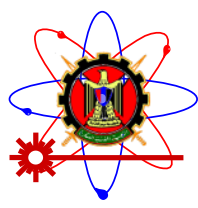

$9^{\text {th }}$ International Conference

on Mathematics and

Engineering Physics

(ICMEP-9)

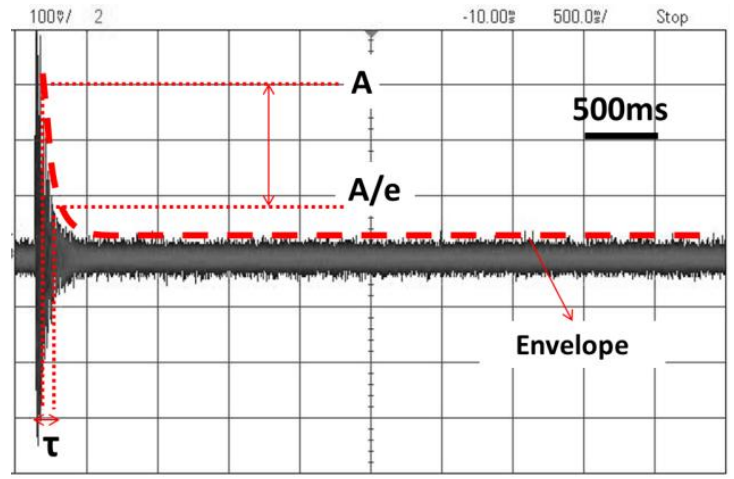

(a)

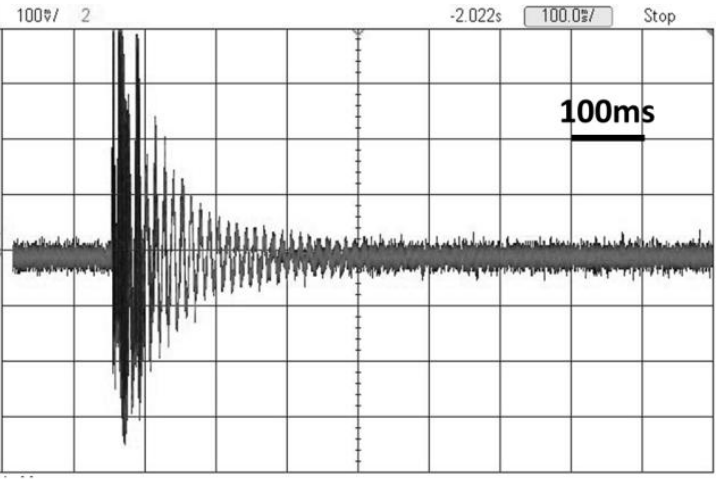

(b)

Figure 14. Oscilloscope picture for the filament impulse vibration pattern at $3300{ }^{\circ} \mathrm{C}$ after a $5 \mathrm{~ms}$ solenoid plunger pulse at different time scales (a) the damping pattern at 500ms /division. (b) The oscillation waveform at $1 \mathrm{~ms}$ /division.

If we study the frequency spectrum of the filament impulse response at room temperature as shown in figure $15 \mathrm{a}$, we notice a single longitudinal vibration at $833 \mathrm{~Hz}$ (denoted 1) and its symmetric complement at $27 \mathrm{HZ}$ that arises because of the double side band signal (DSB) pattern. All symmetric complements are ignored. As the filament temperature continue to increase, it began to lose its stiffness and it may sag under the effect of gravity. At this limit the excitation pulse induces several transversal modes of vibration. Figure 15b shows the filament impulse response at near melting temperature of tungsten, where the main longitudinal frequency mode (denoted 1) was decreased in magnitude and similarly in frequency to $411 \mathrm{~Hz}$. Several strong transversal modes tested by autocorrelation (denoted 2, 3, 4) are also present.

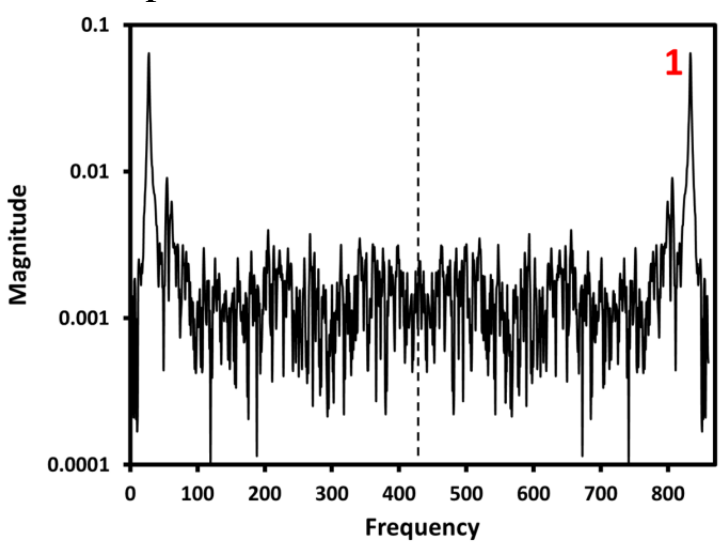

(a)

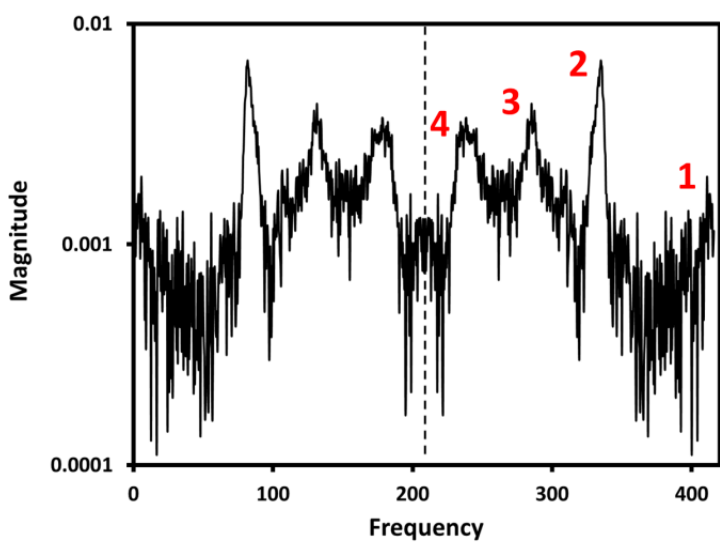

(b)

Figure 15. Symmetric DSB FFT spectrogram for (a) Room temperature impulse pattern of the filament. (b) Near melting temperature impulse pattern of the filament.

Now, If we plot the applied voltage versus the filament current data as shown in figure 16a we notice a very smooth curve leading to the calculation of filament temperature by using equation 19. Then we can plot the main longitudinal frequency versus filament current as 
Military Technical College

Kobry Elkobbah,

Cairo, Egypt

April 3-5,2018

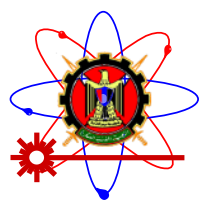

$9^{\text {th }}$ International Conference

on Mathematics and

Engineering Physics

(ICMEP-9)

shown in figure $16 \mathrm{~b}$, to obtain the filament resonance frequency versus its temperature as shown in figure $17 \mathrm{a}$.

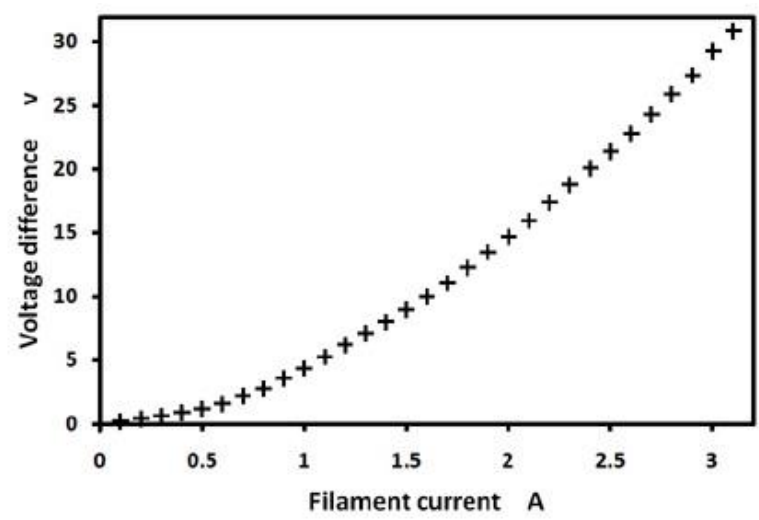

(a)

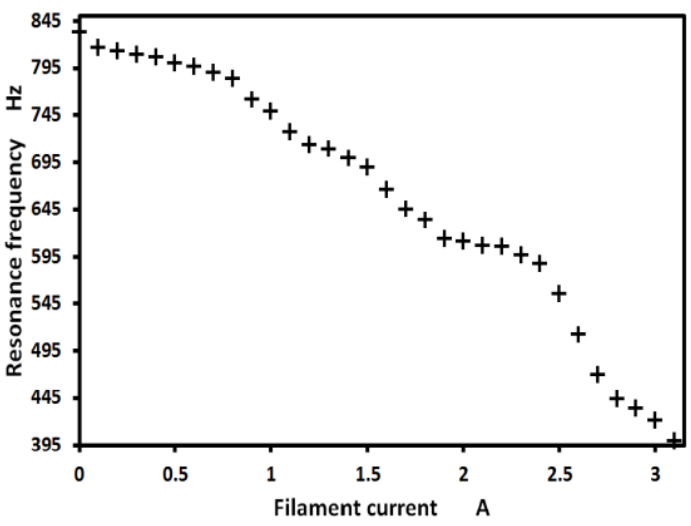

(b)

Figure 16. Filament current versus (a) The applied voltage across filament terminals (b) Filament natural frequency.

Tests revealed that the elastic moduli of tungsten decrease as the temperature of the sample increases till the molting point on three steps. At first a slow decrease in elasticity moduli in the temperature range from room to $1000^{\circ} \mathrm{C}$ is observed, followed by an accelerated decrease till $2600^{\circ} \mathrm{C}$, then suddenly drops to $20 \%$ of its initial value just below melting point. The reason behind this behavior may be ought to $\alpha$ and $\beta$ crystalline phase transition of tungsten occurring at the edges of thermal slope inflections. Both Young and bulk moduli tends to intercept at melting point. This could be explained easily in light of symmetry anisotropy caused by crystalline zones melting.

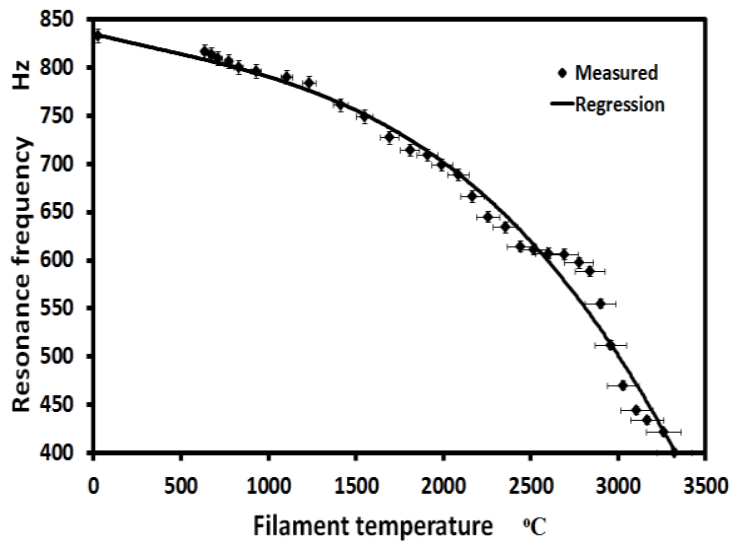

(a)

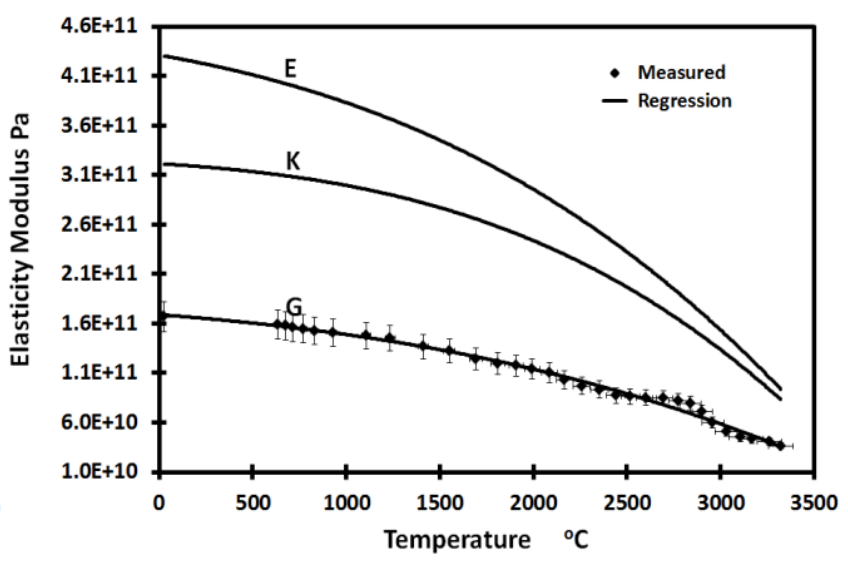

(b)

Figure 17. Filament temperature versus (a) Filament natural frequency. (b) The elasticity moduli of the filament non-sag tungsten.

A remarkable enhancement and decreased of end-loss thermal gradient along the filament length $\mathrm{L}$, is noticed after exceeding a temperature of $800^{\circ} \mathrm{C}$ as revealed by direct filament 
Military Technical College

Kobry Elkobbah, Cairo, Egypt

April 3-5,2018

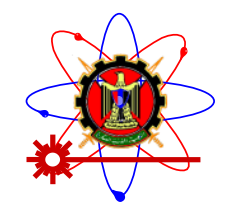

$9^{\text {th }}$ International Conference on Mathematics and Engineering Physics (ICMEP-9)

photography shown in figure 18. Simultaneously, both the natural frequency of the filament and its vibration damping pattern time constant is decreased as the temperature increased as illustrated in the same figure. This decrease is due to the increase in tungsten internal friction as function of temperature [28] which may be described in a separated work.

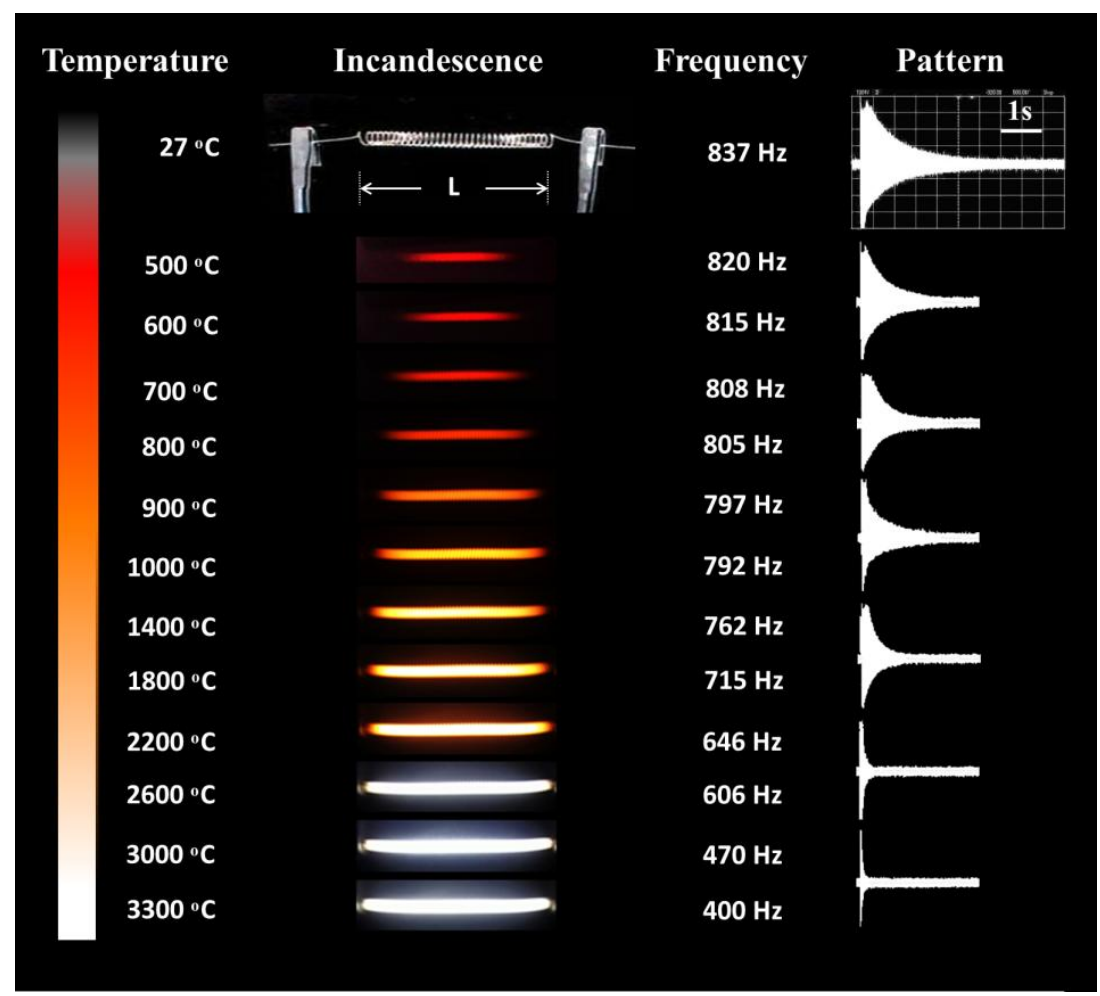

Figure 18. Tungsten filament linear incandescence, natural frequency and impulse damping resonance pattern at different temperatures

Figure19. represents the normalized tungsten filament resistance versus the normalized resonance frequency showing a second order best fit curve. At near melting point the filament resistance is twenty times its room temperature value and the Young's modulus is one fifth its initial value and Hence the elasticity of tungsten is increased five folds at this extent. 
Military Technical College

Kobry Elkobbah,

Cairo, Egypt

April 3-5,2018

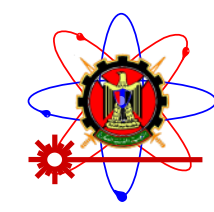

$9^{\text {th }}$ International Conference

on Mathematics and

Engineering Physics

(ICMEP-9)

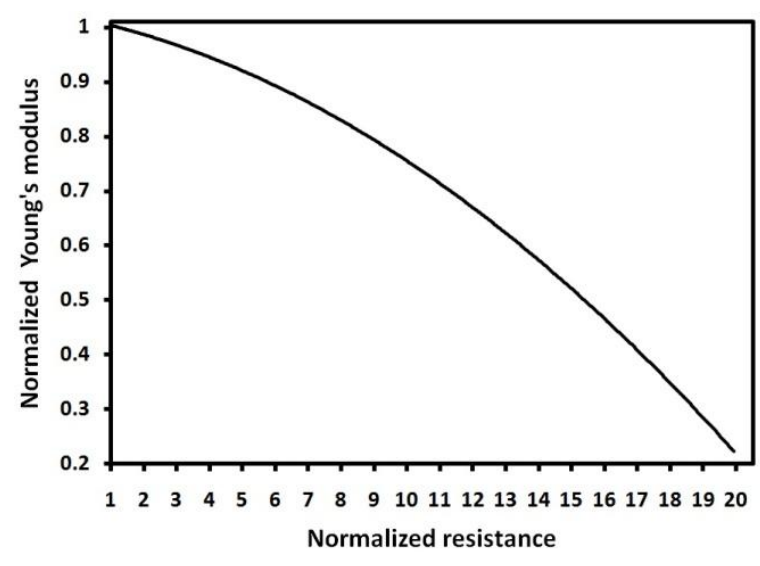

(a)

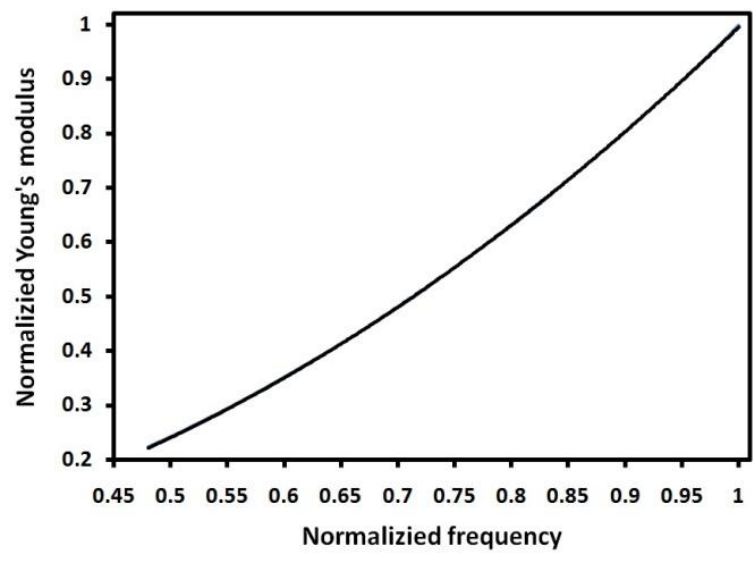

(b)

Figure 19. Normalized regression of (a) Tungsten filament resistance versus Young's modulus (b) Tungsten filament natural frequency versus Young's modulus.

Figure 21a shows the tungsten elasticity moduli as a function of temperature obtained by our work and compared to data calculated using the results of reference [23]

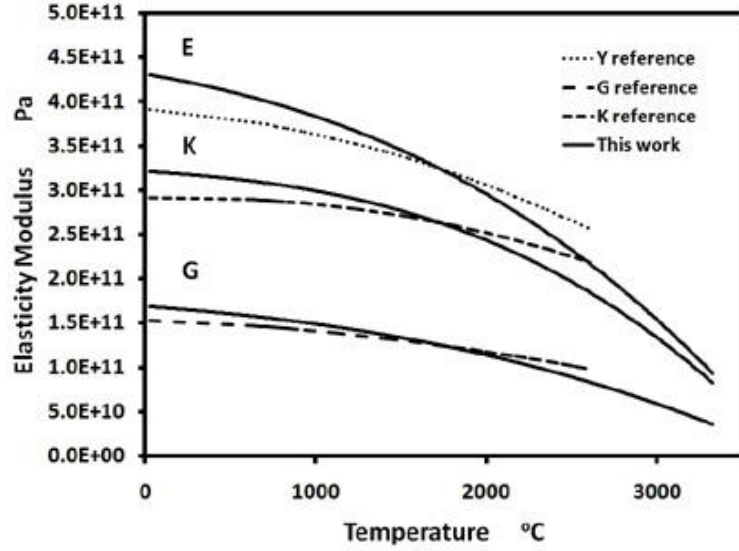

(a)

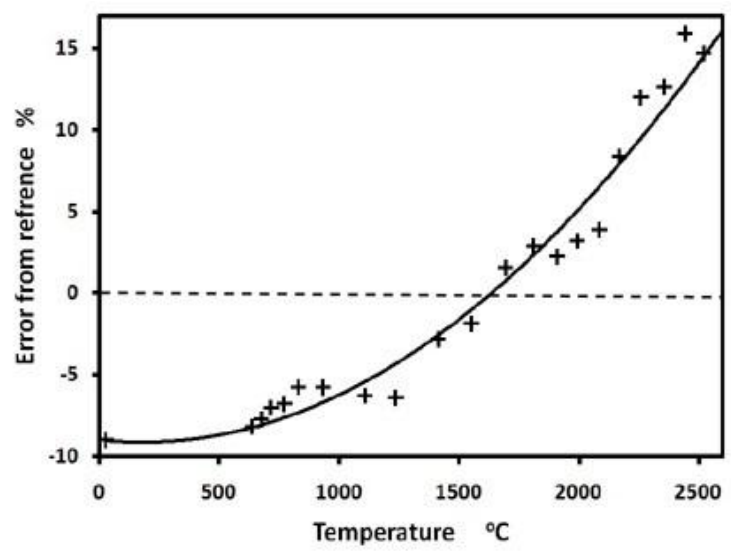

(b)

Figure 20. (a) Elasticity moduli of tungsten obtained in this work compared to those calculated according to the result of reference [23] (b) Deviation percent of the young's modulus results from those of reference [23].

We found that, instead of equation 1, our experimental dynamic Young's modulus results may be better represented by a third order best-fit parametric equation on the form:

$$
E(T)=a_{0}+a_{1} T+a_{2} T^{2}+a_{3} T^{3}
$$

Where $T$ ranges from $27^{\circ} \mathrm{C}$ to $3400^{\circ} \mathrm{C}$ covering the whole range from room temperature to near melting point of tungsten. The value the regression constants $a_{o}, a_{1}, a_{2}$ and $a_{3}$ are given in Table 4. 
Military Technical College

Kobry Elkobbah,

Cairo, Egypt

April 3-5,2018

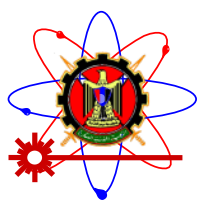

$9^{\text {th }}$ International Conference

on Mathematics and

Engineering Physics

(ICMEP-9)

Table 4. Comparison between the coefficients of parametric regression equations for the Young's modulus experimental data obtained by laser Doppler vibrometry and laser shadowgraphy- based vibrometry.

\begin{tabular}{|l|c|c|c|c|}
\hline Regression coefficients & $\boldsymbol{a}_{\mathbf{0}}$ & $\boldsymbol{a}_{\mathbf{1}}$ & $\boldsymbol{a}_{\mathbf{2}}$ & $\boldsymbol{a}_{\mathbf{3}}$ \\
\hline $\begin{array}{l}\text { For the results of reference [] in the } \\
\text { range from } 27-2650^{\circ} \mathrm{C}\end{array}$ & $391.448 \times 10^{11}$ & $-1.3160 \times 10^{7}$ & $-1.4838 \times 10^{4}$ & 0 \\
\hline $\begin{array}{l}\text { For the results of the present work in } \\
\text { the range from } 27-3400^{\circ} \mathrm{C}\end{array}$ & $4.31117 \times 10^{11}$ & $-3.3174 \times 10^{7}$ & $-1.2315 \times 10^{4}$ & -2.4877 \\
\hline
\end{tabular}

\section{Conclusion}

Changing the symmetry of the tungsten sample from wire string to helical coil in impulse excitation technique, enhances the dynamic elasticity moduli measurements. This enhancement is due to the minimization of temperature gradient over the sample length and decrease the end-loss. Similarly, changing the sample heating method from pulsed current to direct current also eases the measurement and exclude pyrometry from the measurement procedure. The use of shadowgraphy based vibrometry assisted by lock-in photo-detection technique enable low cost measurements, while increasing sample temperature to near melting point. Experimental tests on commercial grade non-sag tungsten filament of P21W lamp, leads to an exclusive third order parametric equation describing the Young's modulus of tungsten from $27^{\circ} \mathrm{C}$ to $3400^{\circ} \mathrm{C}$ measured for the first time. The obtained data is compared to those obtained by laser Doppler vibrometry and pulsed current heating method up to $2650^{\circ} \mathrm{C}$. An agreement between the yield of both method with only $15 \%$ maximum deviation due to the effect of sample impurities on thermo-elastic behavior in our sample and the high thermal gradient of the reference sample. The main finding of our work is, the 5 folds decrease in tungsten Young's modulus was noticed near tungsten melting point as well as the 25 folds increase in internal friction. The method described in this work may be used as noncontact in-plan vibrometry tool for studying vibration of incandescent objects, unlimited by their surface emissivity or roughness. This method may help in the future synthesis and test of new grade of refractory materials, deployed as plasma facing material in the latest fusion reactor or super alloys in critical applications subject to extreme temperature.

\section{Acknowledgment}

The authors are very grateful to the members of Laser Research Technology Center, Engineering Physics Department, Military Technical College, Cairo, Egypt and Physics Department, Faculty of Science, Cairo University and for their support with measurement instruments, encouragement and helpful suggestions. 
Military Technical College

Kobry Elkobbah,

Cairo, Egypt

April 3-5,2018

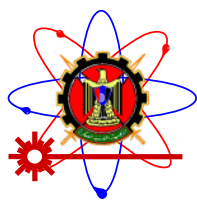

$9^{\text {th }}$ International Conference

on Mathematics and

Engineering Physics

(ICMEP-9)

\section{References}

[1] Aldazabal, J., C. García-Rosales, A. Martín Meizoso, N. Ordás, F. Sordo, J. L. Martínez, and J. Gil Sevillano. "A comparison of the structure and mechanical properties of commercially pure tungsten rolled plates for the target of the European spallation source." International Journal of Refractory Metals and Hard Materials 70 (2018): 45-55.

[2] Meng, QingLing, LiangLiang Niu, Ying Zhang, and GuangHong Lu. "Molecular dynamics simulations of temperature effect on tungsten sputtering yields under helium bombardment." Science China Physics, Mechanics \& Astronomy 61, no. 1 (2018): 017121.

[3] Litnovsky, A., T. Wegener, F. Klein, Ch Linsmeier, M. Rasinski, A. Kreter, B. Unterberg et al. "Smart tungsten alloys as a material for the first wall of a future fusion power plant." Nuclear Fusion 57, no. 6 (2017): 066020.

[4] Marian, J., C. S. Becquart, C. Domain, S. L. Dudarev, M. R. Gilbert, R. J. Kurtz, D. R. Mason et al. "Recent advances in computational materials modeling of tungsten as plasma-facing material for fusion energy applications." Nucl. Fusion 57 (2017).

[5] Koyanagi, Takaaki, NAP Kiran Kumar, Taehyun Hwang, Lauren M. Garrison, Xunxiang Hu, Lance L. Snead, and Yutai Katoh. "Microstructural evolution of pure tungsten neutron irradiated with a mixed energy spectrum." Journal of Nuclear Materials 490 (2017): 66-74.

[6] osemann, P., D. Frazer, M. Fratoni, A. Bolind, and M. F. Ashby. "Materials selection for nuclear applications: Challenges and opportunities." Scripta Materialia (2017).

[7] Igor L. Shabalin, Ultra-High Temperature Materials I: Carbon (Graphene/Graphite) and refractory metals, springer science + business media Dordrechet (2014) ISBN 978-94-007-7586-2.

[8] Lassner, Erik, and Wolf-Dieter Schubert. Tungsten: properties, chemistry, technology of the element, alloys, and chemical compounds. Springer Science \& Business Media, 2012.

[9] Kaufmann, M., and R. Neu. "Tungsten as first wall material in fusion devices." Fusion Engineering and Design 82, no. 5 (2007): 521-527.

[10] Neu, R., R. Dux, A. Kallenbach, T. Pütterich, M. Balden, J. C. Fuchs, A. Herrmann et al. "Tungsten: an option for divertor and main chamber plasma facing components in future fusion devices." Nuclear fusion 45, no. 3 (2005): 209.

[11] Alan Wolfenden (Ed), Dynamic Elastic Modulus Measurements in Materials, Issue 1045 Publisher ASTM International (1990) ISBN 0803112912, 9780803112919,.

[12] R. Pendleton, M. Tuttle, Manual on Experimental Methods for Mechanical Testing of Composites, Springer Science \& Business Media, (2012) ISBN 9400911297, 9789400911291.

[13] Standard test method for dynamic Young's modulus, shear modulus and Poisson ratio for advanced ceramics by impulse excitation of vibration ASTM designation: C1259-95, 1995, pp. 375.

[14] Acsente, Tomy, Raluca Florentina Negrea, Leona Cristina Nistor, Constantin Logofatu, Elena Matei, Ruxandra Birjega, Christian Grisolia, and Gheorghe Dinescu. "Synthesis of flower-like tungsten nanoparticles by magnetron sputtering combined with gas aggregation." The European Physical Journal D 69, no. 6 (2015): 161.

[15] Khani, Arash Hadavand, A. M. Rashidi, and Giti Kashi. "Synthesis of tungsten nanoparticles by reverse micelle method." Journal of Molecular Liquids 241 (2017): 897-903

[16] Sarmah, Trinayan, Ngangom Aomoa, G. Bhattacharjee, Sidananda Sarma, Biswajit Bora, D. N. Srivastava, H. Bhuyan, M. Kakati, and G. De Temmerman. "Plasma expansion synthesis of tungsten nanopowder." Journal of Alloys and Compounds 725 (2017): 606-615.

[17] Enneti, Ravi K. "Synthesis of nanocrystalline tungsten and tungsten carbide powders in a single step via thermal plasma technique." International Journal of Refractory Metals and Hard Materials 53 (2015): 111-116.

[18] Zhou, Le, Frank Kellogg, Clara Hofmeister, Anit Giri, Kyu Cho, and Yongho Sohn. "Nanostructured tungsten through cryogenic attrition." International Journal of Refractory Metals and Hard Materials 52 (2015): 70-77.

[19] Periyannan, S., and K. Balasubramaniam. "Moduli determination at different temperatures by an 
Military Technical College

Kobry Elkobbah,

Cairo, Egypt

April 3-5,2018

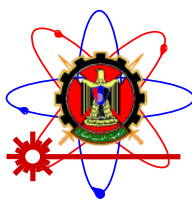

$9^{\text {th }}$ International Conference

on Mathematics and

Engineering Physics

(ICMEP-9)

ultrasonic waveguide method." Experimental Mechanics 56, no. 7 (2016): 1257-1270.

[20] Tillmann, W., U. Selvadurai, and W. Luo. "Measurement of the Young's modulus of thermal spray coatings by means of several methods." Journal of thermal spray technology 22, no. 2-3 (2013): 290298.

[21] Richards, J.T., "An Evaluation of Several Static and Dynamic Methods for Determining Elastic Moduli," Symposium on Determination of Elastic Constants, Special Technical Publication No. 129 of The American Society for Testing Materials, 25 June 1952.

[22] Periyannan, Suresh, and Krishnan Balasubramaniam. "Simultaneous moduli measurement of elastic materials at elevated temperatures using an ultrasonic waveguide method." Review of Scientific Instruments 86, no. 11 (2015): 114903.

[23] Škoro, G. P., J. R. J. Bennett, T. R. Edgecock, S. A. Gray, A. J. McFarland, C. N. Booth, K. J. Rodgers, and J. J. Back. "Dynamic Young's moduli of tungsten and tantalum at high temperature and stress." Journal of Nuclear Materials 409, no. 1 (2011): 40-46

[24] Štubňa, Igor, Anton Trník, and Libor Vozár. "Determination of Young's modulus of ceramics from flexural vibration at elevated temperatures." Acta Acustica united with Acustica 97, no. 1 (2011): 17.

[25] Kogo, Yasuo, Yoshie Iijima, and Naohiro Igata. "Internal friction of carbon-carbon composites at elevated temperatures." Journal of alloys and compounds 355, no. 1 (2003): 148-153.

[26] Dandekar, Dattatraya P., and Anthony G. Martin. "Temperature dependence of flexural and torsional elastic constants of two nickel-based superalloys." Journal of Materials Science 25, no. 7 (1990): 3321-3326

[27] Ashkenazi, J., M. Dacorogna, M. Peter, Y. Talmor, E. Walker, and S. Steinemann. "Elastic constants in $\mathrm{Nb}-\mathrm{Zr}$ alloys from zero temperature to the melting point: Experiment and theory." Physical Review B 18, no. 8 (1978): 4120.

[28] I. BERLEC, "The effect of impurities and heat treatment on the internal on the internal friction of Tungsten at high temperatures", Metallurgical Transactions, 1, 2677-2683, 1970.

[29] Varshni, Y. P. "Temperature dependence of the elastic constants." Physical Review B 2, no. 10 (1970): 3952.

[30] JW Neudecker, CR Sanders, Young's Modulus Measurements to 2500'C by the Thin-Rod Resonance Technique. Advances in Instrumentation. Vol. 24, pt. 2 - Inst. SOC. Am, 1969.

[31] Armstrong, Philip E. ; and Brown, Harry L. : Dynamic Young's Modulus Measurement Above 1000 $\mathrm{C}$ on Some Pure Polycrystalline Metals and Commercial Graphites. Trans. AIME, vol. 230, no. 5, Aug. 1964, pp. 962-966.

[32] Robinson, S. L., and O. D. Sherby. "Mechanical behavior of polycrystalline tungsten at elevated temperature." Acta Metallurgica 17, no. 2 (1969): 109-125.

[33] Carnevale, Edmund H. "Acoustic techniques and applications at elevated temperatures." NASA Special Publication 132 (1967): 73.

[34] Lowrie, Robert; Gonas, A. M. Single crystal Elastic Properties of Polycrystalline Tungsten, $24^{\circ}-$ $1800^{\circ} \mathrm{C}$, Journal of Applied Physics, 38, 7, p.4505-4509 (1967).

[35] Lytton, Jack L., John A. Hren, Kenneth T. Kamber, and Oleg D. Sherby. "Apparatus for the determination of dynamic Young's modulus and internal friction in vacuum at temperatures from $25^{\circ}$ C to $1200^{\circ}$ C." British Journal of Applied Physics 15, no. 12 (1964): 1573.

[36] Brown, Harry L., and Philip E. Armstrong. "Young's Modulus Measurements above 2000 C." Review of Scientific Instruments 34, no. 6 (1963): 636-639.

[37] W. Hl. Hill, K. E. Shimmin, Elevated Temperature Dynamic Elastic Moduli Of Various Metallic Materials, MATERIALS CENTRAL,Wright Air Development Division, Wadd Technical REPORT 60-13874, 1961.

[38] Fine, M.E., "Dynamic Methods for Determining the Elastic Constants and their Temperature Variation in Metals," Symposium on Determination of Elastic Constants Special Technical Publication No. 129 of the American Society for Testing Materials, 25 June 1952.

[39] Hill, W. H., and K. D. Shimmin. Elevated temperature dynamic elastic moduli of various metallic materials. METAL HYDRIDES INC BEVERLY MA, 1961.

[40] Lees, Chas H., Jas P. Andrews, and L. S. Shave. "The variation of Young's modulus at high 
Military Technical College

Kobry Elkobbah,

Cairo, Egypt

April 3-5,2018

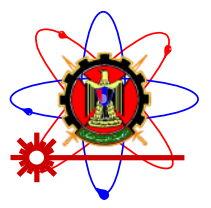

$9^{\text {th }}$ International Conference

on Mathematics and

Engineering Physics

(ICMEP-9)

temperatures." Proceedings of the Physical Society of London 36, no. 1 (1923): 405.

[41] Andrews, Jas P. "The variation of Young's Modulus at high temperatures." Proceedings of the Physical Society of London 37, no. 1 (1924): 169.

[42] Agrawal, D. C. "The Coiling Factor in the Tungsten Filament Lamps." Lat. Am. J. Phys. Educ. Vol 5, no. 2 (2011): 443.

[43] Halas, S. and Durakiewicz, T.,. Temperature distribution along a metal filament heated in vacuum by DC current. Vacuum, 49(4), pp.331-336. (1998)

[44] Jain, S. C., and K. S. Krishnan. "The Distribution of Temperature along a Thin Rod Electrically Heated In vacuo. IV. Many Useful Empirical Formulae Verified." In Proceedings of the Royal Society of London A: Mathematical, Physical and Engineering Sciences, vol. 225, no. 1160, pp. 1932. The Royal Society, 1954.

[45] Prins, J. A., J. Schenk, and J. M. Dumoré. "Temperature distribution at the end of a hot wire." Applied Scientific Research 3, no. 4 (1952): 272-278.

[46] Worthing, A. G. "Theory of end-loss corrections and its application to uniform, electrically heated tungsten filaments in vacuo." Journal of the Franklin Institute 194, no. 5 (1922): 597-611.

[47] Langmuir, Irving. "The characteristics of tungsten filaments as functions of temperature." Physical Review 7, no. 3 (1916): 302.

[48] J. Vass, R. Smid, R.B. Randall, P. Sovka, C. Cristalli, B. Torcianti, Avoidance of speckle noise in laser Vibrometry by the use of kurtosis ratio: Application to mechanical fault diagnostics, Mechanical Systems and Signal Processing 22, 647-671, 2008.Castellini, M. Martarelli, E.P.

[49] Tomasini, Laser Doppler Vibrometry: Development Of Advanced Solutions Answering to Technology's needs, Mechanical systems and Signal Processing 20, 12651285, 2006.

[50] A. M. Wahl, Mechanical Springs, 2nd Edition, McGraw-Hill, Inc., New York, 1963.

[51] Gere, James M. "Mechanics of Materials, th 5 ed." USA: Brooks/Cole (2001).

[52] D. C. Agrawal, V. J. Menon, "Light bulb exponent-rules for the classroom", IEEE Transactions on Education, 43, 262-265, 2000.

[53] E. G. Wolff, Measurement Techniques for Low Expansion Materials, 9th National SAMPE Technical Conference, AtlantaGa, 9, 57-72, 1977.

[54] Monier, Romain, François Thumerel, Julien Chapuis, Fabien Soulié, and Cyril Bordreuil. "Liquid metals surface temperature fields measurements with a two-colour pyrometer." Measurement 101 (2017): 72-80

[55] Cadar, Sergiu, Dorin Petreuş, Etz Radu, Frențiu Tiberiu, Darvasi Eugen, and Sanziana Butaciu. "Temperature and power consumption for tungsten coil in the drying process of liquid samples." In Electronics Technology (ISSE), 2016 39th International Spring Seminar on, pp. 348-352. IEEE, 2016.

[56] H.H. Hassan, S.A. Khairy and H.S. Ayoub, A Simple Laboratory Experiment for Measuring the Expansivity of Tungsten at Elevated Temperatures, Nature and Science; 13(11), 146-151, 2015.

[57] Dauphin, M., S. Albin, M. El Hafi, Y. Le Maoult, and F. M. Schmidt. "Towards thermal model of automotive lamps." In 11th International Conference on Quantitative InfraRed Thermography. 2012

[58] Sobczyk, Zbigniew. "Total current measurement interrupts detection method in automotive bulbs circuits." Journal of KONES 18 (2011): 579-584.

[59] De Izarra, Charles, and Jean-Michel Gitton. "Calibration and temperature profile of a tungsten filament lamp." European Journal of Physics 31, no. 4 (2010): 933.C.

[60] Calzà, G., L. M. Gratton, T. López-Arias, and S. Oss. "Very fast temperature measurement with a thin lamp filament." Physics Education 47, no. 3 (2012): 334.

[61] Gluck, Paul, and John King. "Physics of incandescent lamp burnout." The Physics Teacher 46, no. 1 (2008): 29-35. 